\title{
Normalisation and Stigmatisation of Obesity in UK Newspapers: a Visual Content Analysis
}

\author{
Mr. Chris Patterson* and Dr. Shona Hilton
}

MRC/CSO Social and Public Health Sciences Unit, University of Glasgow, UK

\begin{abstract}
Obesity represents a major and growing global public health concern. The mass media play an important role in shaping public understandings of health, and obesity attracts much media coverage. This study offers the first content analysis of photographs illustrating UK newspaper articles about obesity. The researchers studied 119 articles and images from five major national newspapers. Researchers coded the manifest content of each image and article and used a graphical scale to estimate the body size of each image subject. Data were analysed with regard to the concepts of the normalisation and stigmatisation of obesity. Articles' descriptions of subjects' body sizes were often found to differ from coders' estimates, and subjects described as obese tended to represent the higher values of the obese BMI range, differing from the distribution of BMI values of obese adults in the UK. Researchers identified a tendency for image subjects described as overweight or obese to be depicted in stereotypical ways that could reinforce stigma. These findings are interpreted as illustrations of how newspaper portrayals of obesity may contribute to societal normalisation and the stigmatisation of obesity, two forces that threaten to harm obese individuals and undermine public health efforts to reverse trends in obesity.
\end{abstract}

Keywords: BMI, content analysis, images, media, newspaper, normalisation, obesity, stigma.

\section{INTRODUCTION}

Obesity is a major, and growing, public health concern. Globally, obesity affects more than one in ten adults, and prevalence has more than doubled since 1980 [1]. In 2009, $22 \%$ of men and $24 \%$ of women [2] in England were obese (defined as a BMI greater than, or equal to, 30 [3]), as were $27 \%$ of men and $28 \%$ of women in Scotland [4]. Obesity's rapid growth and links to increased mortality and morbidity [5] have led the global obesity problem to be described as an epidemic [6].

Explanations for the causes of obesity have changed over time. Focus has recently shifted somewhat away from viewing obesity as a consequence of negative individual behaviour and towards viewing it as a social and environmental phenomenon [7,8], and one that can be viewed as a natural human response to overwhelming environmental influences $[5,6]$. In their history of the medicalisation of obesity, Chang and Christakis [9] observe that: 'Initially cast as a social parasite, the [obese] patient is later transformed into a societal victim' (p.155). Underpinning the structurally-driven obesity epidemic is the 'obesogenic environment', a combination of features of the post-industrial built, economic, political and sociocultural environments that create barriers to healthy eating and active lifestyles [10, 11]. Hill and colleagues [6] suggest that: 'in pursuing the good life people have created an environment and a society that unintentionally promote weight gain and

*Address correspondence to this author at the MRC/CSO Social and Public Health Sciences Unit, University of Glasgow, 4 Lilybank Gardens, Glasgow, G12 8RZ, UK; Tel: + 44141357 3949; Fax: + 44141337 2389; E-mail: chris.patterson@glasgow.ac.uk obesity, given peoples' genetic and biological make-up' (p.20).

The mass media are an important part of the sociocultural environment. Agenda-setting theory illustrates how mass media are instrumental in setting the public agenda, determining the issues to which people are exposed, and what information they receive about those issues [12]. The mass media reflect, reinforce and shape common culture, including public health-related beliefs and behaviours [12, 13]. Media interest in obesity has grown quickly over the past two decades $[8,14]$, coexisting with increases in the incidence of overweight and obesity in the UK and worldwide [15]. The increasing quantity of reporting about obesity, coupled with ability of mass media to help define public understandings of health issues, means that the media represent an important element of the obesogenic environment.

One way that mass media could influence public understandings and perceptions of obesity is by contributing to its normalisation. Normalisation of obesity is a cyclical process by which shifting public perceptions of weight lead to increases in population adiposity, exacerbating the obesity problem [16-18]. Underpinning this theory is the concept that as average body mass increases within a population, so does that population's familiarity with, and acceptance of, increased body mass. Increased acceptance may prevent individuals from recognising, and attempting to regulate, unhealthy adiposity in themselves, exacerbating the prevalence of obesity and likely increasing population mortality and morbidity [5]. Keightley and colleagues [18] describe how normalisation might condition individuals to rationalise obesity in themselves: 
'It is possible that the increase in the proportion of the population who are overweight or obese may have resulted in a normalising effect on perceptions of weight and as a result, thus changing the social ideology of being fat. That is, the threshold of what has been deemed 'fat' in the community may be rising to accommodate increased average weights in the population. It is possible therefore, that through social conditioning, individuals may rationalise the extent and/or risks of obesity based on a perception of physical fitness and social conditioning of body morphology.'

\section{KEIGHTELY, CHUR-HANSEN, PRINCI \& WITTERT, P.E342}

Moffat [19] suggests that, despite objections by some researchers that the obesity epidemic is characterised by unhealthy moral panic and alarmism, many health professionals fear that the normalisation of obesity has generated a dangerous apathy about the health risks of obesity. In addition to media representations, potential drivers of normalisation include 'vanity sizing', the phenomenon of clothing retailers labelling their garments as smaller than they are [20], growing food portion sizes [21] and the increasing medicalisation of obesity $[17,22]$.

A wealth of evidence highlights shifting societal perceptions of weight [23]. Overweight and obese individuals increasingly underestimate their own weight $[16$, 24] and parents often fail to recognise obesity in their children [25, 26]. For example, Johnson and colleagues' [16] comparison of two UK household surveys from 1999 and 2007 found that increases in self-reported weight over time were matched by an increase in the body-size threshold at which respondents deemed themselves to be overweight. Overweight and obese respondents to the 2007 survey were less likely to describe their weight status accurately than were their 1999 counterparts. The researchers note that this shift occurred despite of public health campaigns and elevated news reporting on the topic of overweight and obesity. Duncan and colleagues [27] studied the relationship between weight perceptions and weight-related attitudes in the United States. Their analysis of survey data found that overweight and obese respondents who misperceived their weight were much less likely to want to lose weight, and to have tried to lose weight, than those who perceived their weight accurately. This suggests misperception of weight can act as a barrier to adopting healthy lifestyles.

In addition to a decline in individuals' ability to accurately assess their own weight, there is evidence that obesity stigma could undermine efforts to tackle the obesity problem [28]. Stigma is commonly defined in terms of identifying certain characteristics as deviant from widelyaccepted societal norms, and therefore marking individuals who embody those characteristics as undesirable outsiders [29]. Link and Phelan [29] identify four interrelated components that converge to create stigma: distinguishing and labelling human differences; linking the labelled individuals to negative stereotypes; separating labelled individuals from those without the undesirable characteristics; and finally discrimination and the resulting social disadvantage of the labelled persons. This model can be applied to the process of stigmatisation of obese individuals: humans are be labelled by their BMI category; obese BMI is often associated with negative stereotypes including greed, sloth and lack of discipline [30]; the obese population is often mentioned as a specific societal group; and obese individuals can be subject to discrimination and disadvantage in various social spheres [31].

Obesity stigma has consequences for both psychological and physical health. Psychological consequences include depression, self-esteem, body-image dissatisfaction, and unhealthy coping strategies. Crucially, stigma does not appear to provoke the adoption of healthier lifestyles. On the contrary, evidence suggests that stigmatisation increases binge-eating [32,33] and threatens physical health [31]. As such, it is vital that public health efforts to reduce obesity do not stigmatise it. There is some evidence that media representations might contribute to the stigmatisation of obesity $[28,30]$, but as yet this issue has received relatively little attention.

One aspect of newsprint coverage that content analyses often overlook is the images that illustrate articles. There is evidence that images can significantly influence readers' interest in, and interpretations of, news articles [34, 35], and that news consumers can recall news images long after their memory of the content of the accompanying text has faded [36]. The power of news images is such that there is value in analysing them in addition to text. Gollust and colleagues [37] analysed descriptive and demographic features of images of overweight and obese individuals published in American news magazines, and Heuer and colleagues [38] performed a similar analysis of photographs accompanying American online news stories about obesity. Both of these studies found that image subjects were often depicted engaged in stereotypical behaviours, including eating junk food and watching television. Due to news images' potential to influence readers' perceptions, these stereotypical depictions may reinforce damaging stigma. Furthermore, Lewis and colleagues [39] suggest that the subtle forms of stigma reproduced in banal forms such as newspaper representations tend to be the most harmful in terms of health and social wellbeing. Heuer and colleagues [38] suggest that the stigmatising depictions may cause blame for obesity to be attributed to obese individuals, which is directly at odds with the goals of public health policy to address obesity as a social and environmental issue.

The normalisation and stigmatisation of obesity are two damaging phenomena in which mass media portrayals may play a role. In this study, we investigate how UK newspapers might contribute to each of those phenomena. We analyse the photographs used to illustrate newspaper articles about obesity with reference to the text that accompanies them to examine how articles represent obesity. Our research questions are, firstly, to what extent might newspaper images of obesity contribute to the normalisation of obesity, and secondly, how might they contribute to the stigmatisation of obesity. To answer the first research question, we analyse the differences between article authors' written descriptions of image subjects' body sizes and researchers' visual estimates of those subjects' body sizes. Visual estimation of BMI is less accurate than true physical measures, but is used routinely by doctors to diagnose obesity [40]. Disparities between these descriptions and evaluations may be important 
Table 1. Articles in Sample by Publication and Genre

\begin{tabular}{|c|c|c|c|c|c|}
\hline \multirow{2}{*}{ Genre } & \multicolumn{2}{|c|}{ Genre Totals } & \multirow{2}{*}{ Publication } & \multicolumn{2}{|c|}{ Publication Totals } \\
\hline & Count & $\%$ & & Count & $\%$ \\
\hline Serious & 13 & 10.9 & Independent \& Independent on Sunday & 13 & 10.9 \\
\hline \multirow{2}{*}{ Mid-market } & \multirow{2}{*}{47} & \multirow{2}{*}{39.5} & Daily Mail \& Mail on Sunday & 22 & 18.5 \\
\hline & & & Express \& Sunday Express & 25 & 21.0 \\
\hline \multirow{3}{*}{ Tabloid } & \multirow{2}{*}{59} & \multirow{2}{*}{49.6} & Mirror \& Sunday Mirror & 41 & 34.5 \\
\hline & & & The Sun \& News of the World & 18 & 15.1 \\
\hline & 119 & 100.0 & & 119 & 100.0 \\
\hline
\end{tabular}

because they could cause readers to form an inaccurate impression of what body sizes range is considered to be obese, particularly if these skewed perceptions are reinforced repeatedly over time. In answering the second research question, we analyse the occurrence of a set of potentially stigmatising and stereotyping features in images, and how the appearance of these features relates to the body size represented. To our knowledge, this is the first content analysis of UK newspapers' coverage of obesity that analyses both images and text, and the first that employs visual estimates of body size.

\section{METHOD}

\section{Sample Selection and Collection}

A representative sample of five national daily UK newspapers and their corresponding Sunday counterparts were selected. The selection represented three genres, and consisted of one 'serious' newspaper (The Independent \& The Independent on Sunday), two 'mid-market tabloid' newspapers (The Daily Mail \& The Mail on Sunday; The Express \& The Sunday Express) and two 'tabloids' (The Mirror \& The Sunday Mirror; The Sun \& The News of the World). This typology has been used in other analyses of print media discourse to select a broad sample of newspapers with various readership profiles and political orientations [41]. Publications were chosen on the basis of having high circulation figures (www.nrs.co.uk) and indicating the inclusion of images in their database entries for articles.

Keyword searches were conducted on the Nexis UK and NewsBank databases to identify articles related to obesity published between 1st January 1996 and 31st December 2010. The time period was chosen to incorporates a short period prior to the WHO's 1997 warning about the obesity epidemic [42] and the subsequent rise in newspaper reporting on obesity over the following 15 years [8]. An initial search was carried out for articles featuring the search terms "obesity", "obese", "fat nation", "fatties" or "lardy" in the headline. To determine relevant search terms, two researchers read a selection of articles about obesity and noted terms that were used commonly.

The initial search retrieved 3,878 articles. The articles were manually sorted based on two initial inclusion criteria: human obesity must be the primary topic of the article, and the article must not be from the letters, television guide or television reviews sections of the publication. Following application of the inclusion criteria, 1,698 relevant articles were retained. The remaining articles were scrutinised for indications that they contained images, either in the form of references to an image in the text, or in the inclusion of image captions. Of the 1,698 relevant articles, 344 indicated that they contained images. As the online newspaper databases used do not store images with articles, original printed copies of the articles were retrieved from the newspaper archives of the National Library of Scotland (NLS). Due to limitations of the archives, 133 of the list of 344 articles with images were retrieved. These 133 images were each examined, and those that were cartoons or did not feature people were excluded. The final sample comprised 119 articles and images (Table 1). In the case of articles that contained more than one image, the largest or most prominent image was used. If more than one person was pictured in the image, the most central or prominent person was used.

\section{The Figure Rating Scale}

A figure rating scale was used to assess subjects' body sizes. Figure rating scales are commonly used in studies of body image disturbance [43] and generally do not include BMI values. For this study it was necessary to use a scale that attributes a BMI value to each portrait so that body sizes observed by the coders could be assigned to BMI categories. The body image instrument developed by Pulvers and colleagues [44], which has been tested for content validity, was chosen, and BMI values ranging from 16 to 40 were applied to each portrait in increments of three BMI points based on the authors' guidance [44, p.1642] (Fig. 1). Coders identified the portrait on the scale that most closely resembled each newspaper image, and assigned each image a rating between one to nine accordingly. To minimise the effect of the pre-existing knowledge of the BMI scale, BMI values and categories were not included in the scale provided to coders. Values and categories based on World Health Organisation [3] classifications have been included in Fig. (1) for illustrative purposes.

\section{The Coding Frame}

A coding frame for recording features of the images and articles was developed. Researchers $(\mathrm{CP}, \mathrm{SH})$ examined images to create thematic categories capturing information about image subjects and the contexts in which they were photographed. Additional categories were developed to record descriptive details of articles including publication 


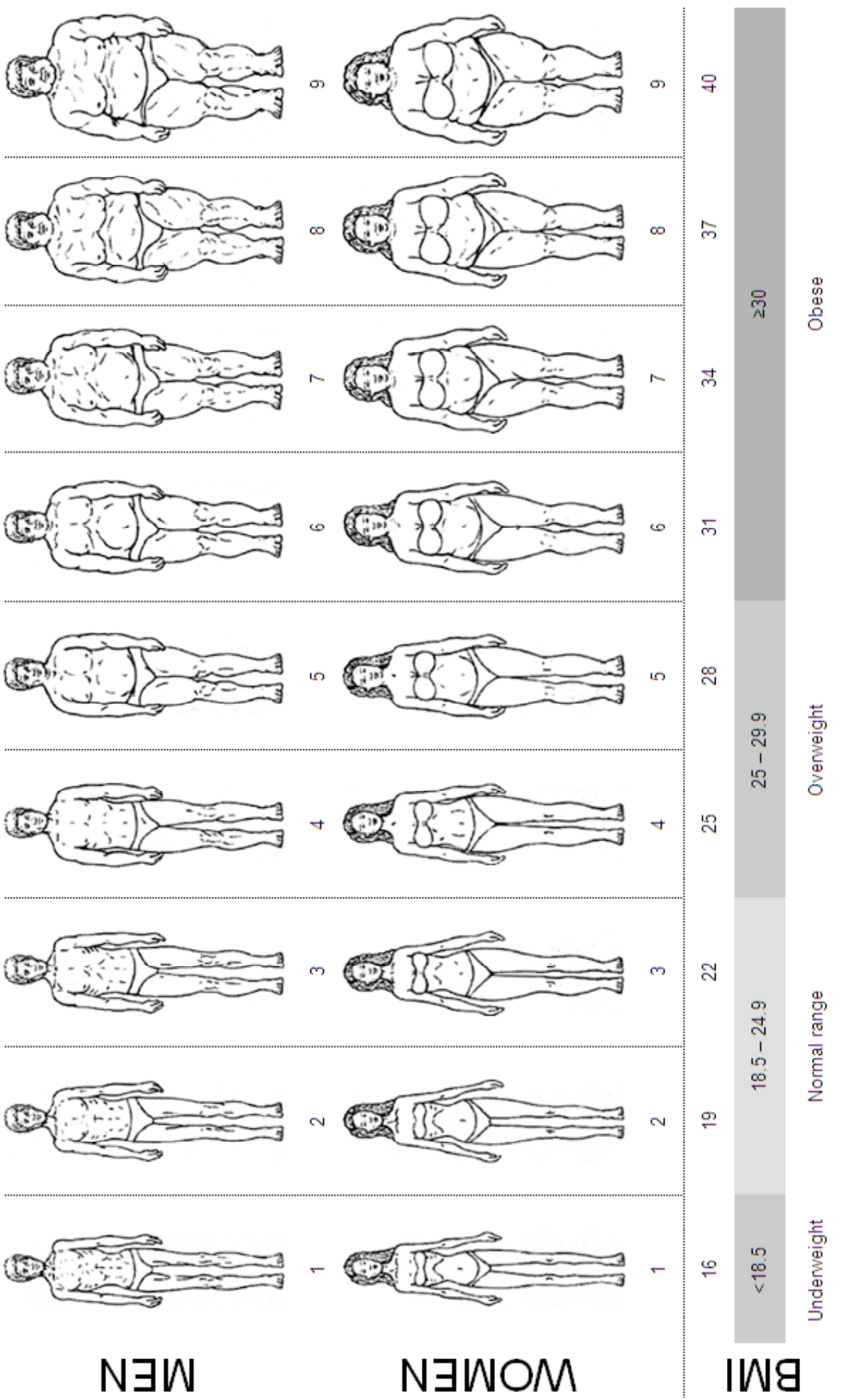

Fig. (1). Visual BMI rating scale adapted from Pulvers and colleagues' (2004) body image instrument.

date, publication title and how the subject's body size is described in the text. While articles did not always specifically describe their image subjects' body size, such as when a stock image was used to illustrate obesity in general, coders attributed the predominant body size description used in the article to the image used to illustrate it. This approach was chosen to take into account the associations that the reader might perceive, rather than associations that the author may have intended to create.

The initial coding frame was piloted with seven researchers who coded batches of images and suggested 
further improvements. The final coding frame included two contextual codes and eleven conceptual codes. The contextual codes comprised a unique identification code assigned to each image, and the caption associated with the image, if any. Conceptual codes comprised: body size described in article text; sex; age group; clothing; pose; body parts visible; body angle depicted; photography location; facial expression; the presence of family or others in the image; and obesity-related behaviours depicted.

\section{CODING AND ANALYSIS}

The thematic content of each image and its accompanying text were coded by CP. The body size depicted in each image was coded by four coders who assigned each image a value between one and nine using the figure rating scale. Using four coders ensured that any systematic coding biases could be identified. Discrepancies between coders' evaluations of images allowed researchers to identify images that were posed in such a way that parts of the body were obscured, making reasonable estimations of body size difficult to achieve. Those images that produced significant disagreement between coders were not coded. The coded images were assigned BMI categories based on WHO classifications [1]: a BMI between 18.5 and 24.9 was considered to be 'normal range', 25-29.9 'overweight' and $30+$ 'obese'.

Data from completed coding frames were entered into SPSS 15. A key part of the analysis was identifying the degree to which articles' written descriptions of subjects' body sizes agreed with coders' evaluations of those body sizes. Any articles in which the written descriptions of subjects differed from coders' evaluations could be interpreted as misrepresenting body size, and if a large proportion of articles in the sample were found to be misrepresentative, this might be indicative of a trend of misrepresentation of body size in newsprint coverage of obesity.

Fleiss' Kappa was used to measure inter-rater agreement between coders' ratings of image subjects' BMI categories, and Cohen's Kappa was used to measure agreement between article authors' written descriptions and coders' visual evaluations.

\section{RESULTS}

\section{Sample Characteristics}

The sample comprised 119 images from articles published between 1998 and 2010 (Table 1). Almost half of subjects were males $(n=53)$ and just over half female $(n=64)$. The sex of two subjects could not be determined. A third $(n=39)$ of subjects were assessed to be young children $(\leq 12$ years), a tenth $(n=12)$ teenagers $(13-18$ years $)$, and half $(\mathrm{n}=58)$ adults $(\geq 19$ years). The age groups of ten subjects could not be determined. Almost two thirds $(n=74)$ of subjects were pictured alone, and a third $(n=45)$ with others. Two thirds $(n=79)$ of subjects were dressed in casual clothes, 17 were smartly dressed and three were depicted as untidy. Five subjects wore clothing associated with being a medical patient, while a tenth $(\mathrm{n}=14)$ of subjects were partially clothed (Table 2).

\section{Subject behaviours}

Subjects' obesity-related behaviours were recorded. Five were pictured watching television, and 28 were pictured with food, often junk food. Subjects' poses were also coded. A quarter $(n=29)$ were sitting or reclining, six engaged in exercise and the remaining $82(68.9 \%)$ were standing or walking. Of those subjects with visible facial expressions, 37 (45.1\%) were happy, 10 unhappy and 35 (42.7\%) neutral (Table 2).

\section{Varying Descriptions of Body Size}

Eighty-three articles described subjects' body sizes in the article text. Ten were described as 'normal' (including 'healthy' and 'slim'), 13 as overweight and 60 as obese. Coders assessed the body sizes of 105 (88.2\%) subjects using the figure rating scale. Fourteen were not coded because they were either too small or awkwardly posed to be evaluated reliably, highlighted by a lack of agreement between coders. Of the subjects coded, seven were judged to be in the 'normal' weight range (BMI 18.50-24.99), 13 overweight (BMI 25.00-29.99) and 85 obese (BMI 30.00+). Of the seven images coded as normal weight, four were of individuals who were once obese but had lost weight, two were from articles about exercise classes in schools, and one was from a story about a trend of dieting among girls aged between 11 and 16. A Fleiss' Kappa test of agreement on BMI category between the four coders returned a Kappa of 0.617 , which can be interpreted as substantial agreement [45].

Articles' descriptions of body sizes were compared with coders' estimates of those subjects' body sizes. A Cohen's Kappa test of agreement returned a result of 0.361 , which can be interpreted as fair agreement [45]. Table $\mathbf{3}$ provides an overview of the lack of agreement between descriptions and coders' estimates. Of the eight subjects estimated by coders to be overweight, two were described as overweight and the remaining six as normal. Of the 64 subjects coded by coders as obese, one was described as normal range, 10 overweight and 53 obese. Table 4 details the distribution of the BMI values of the 53 subjects that were both described in article text as 'obese'. On the figure rating scale (Fig. 1), the obese category is represented by portraits $6,7, \mathbf{8}$ and 9 , representing BMI values $31,34,37$ and 40 respectively. Table 4 demonstrates that BMI values were not evenly distributed between subjects described by articles as being obese. Subjects tended to represent higher BMI values within the obese range, and the most commonly represented BMI value was 40 .

\section{Relationships Between Body Size and other Characteristics}

Researchers recorded the angle from which each subject was photographed and the visibility of each subject's face. The 10 subjects described as normal weight range were all pictured with their faces visible and facing the camera. Of the 37 subjects shown without their faces visible, five were described as overweight and 28 obese (Table 2 ).

Subjects described as overweight or obese were depicted as untidy, casually dressed, wearing clothing associated with being a medical patient, or partially clothed more frequently 
Table 2. Subject Characteristics and Behaviours

\begin{tabular}{|c|c|c|c|c|c|c|c|c|}
\hline & \multicolumn{8}{|c|}{ Body Type Described in Text } \\
\hline & \multicolumn{2}{|c|}{ Normal Weight } & \multicolumn{2}{|c|}{ Overweight } & \multicolumn{2}{|c|}{ Obese } & \multicolumn{2}{|c|}{ Not Described } \\
\hline & \multicolumn{2}{|c|}{$(n=10)$} & \multicolumn{2}{|c|}{$(n=13)$} & \multicolumn{2}{|c|}{$(n=60)$} & \multicolumn{2}{|c|}{$(n=36)$} \\
\hline & Count & $\%$ & Count & $\%$ & Count & $\%$ & Count & $\%$ \\
\hline \multicolumn{9}{|c|}{ Sex of subject } \\
\hline Male & 2 & 20.0 & 6 & 46.2 & 28 & 46.7 & 17 & 47.2 \\
\hline Female & 8 & 80.0 & 7 & 53.8 & 30 & 50.0 & 19 & 52.8 \\
\hline Unknown & 0 & 0.0 & 0 & 0.0 & 2 & 3.3 & 0 & 0.0 \\
\hline \multicolumn{9}{|c|}{ Age group } \\
\hline Child (0-12) & 1 & 10.0 & 8 & 61.5 & 16 & 26.7 & 14 & 38.9 \\
\hline Teenager (13-18) & 1 & 10.0 & 0 & 0.0 & 6 & 10.0 & 5 & 13.9 \\
\hline Adult (19+) & 8 & 80.0 & 5 & 38.5 & 29 & 48.3 & 16 & 44.4 \\
\hline Age unknown & 0 & 0.0 & 0 & 0.0 & 9 & 15.0 & 1 & 2.8 \\
\hline \multicolumn{9}{|c|}{ People in picture } \\
\hline Subject alone & 6 & 60.0 & 5 & 38.5 & 41 & 68.3 & 22 & 61.1 \\
\hline With others & 4 & 40.0 & 8 & 61.5 & 19 & 31.7 & 14 & 38.9 \\
\hline \multicolumn{9}{|c|}{ Sedentary activities } \\
\hline Yes & 0 & 0.0 & 0 & 0.0 & 5 & 8.3 & 0 & 0 \\
\hline No & 10 & 100.0 & 13 & 100.0 & 55 & 91.7 & 36 & 100 \\
\hline \multicolumn{9}{|c|}{ Eating } \\
\hline Yes & 0 & 0.0 & 2 & 15.4 & 19 & 31.7 & 29 & 80.6 \\
\hline No & 10 & 100.0 & 11 & 84.6 & 41 & 68.3 & 7 & 19.4 \\
\hline \multicolumn{9}{|c|}{ Pose of subject } \\
\hline Reclining/sitting & 0 & 0.0 & 4 & 30.8 & 15 & 25.9 & 10 & 27.8 \\
\hline Standing still & 10 & 100.0 & 7 & 53.8 & 29 & 50.0 & 19 & 52.8 \\
\hline Moving & 0 & 0.0 & 2 & 15.4 & 14 & 24.1 & 7 & 19.4 \\
\hline \multicolumn{9}{|c|}{ Facial expression } \\
\hline Happy & 9 & 90.0 & 2 & 15.4 & 8 & 13.3 & 18 & 50.0 \\
\hline Unhappy/neutral & 1 & 10.0 & 6 & 46.2 & 24 & 40.0 & 14 & 38.9 \\
\hline Not visible & 0 & 0.0 & 5 & 38.5 & 28 & 46.7 & 4 & 11.1 \\
\hline \multicolumn{9}{|c|}{ Clothing } \\
\hline Untidy & 0 & 0.0 & 0 & 0.0 & 3 & 5.1 & 0 & 0.0 \\
\hline Casual & 6 & 60.0 & 6 & 46.2 & 43 & 72.9 & 24 & 66.7 \\
\hline Smart & 3 & 30.0 & 2 & 15.4 & 5 & 8.5 & 7 & 19.4 \\
\hline Medical & 0 & 0.0 & 1 & 7.7 & 3 & 5.1 & 1 & 2.8 \\
\hline Partially clothed & 1 & 10.0 & 4 & 30.8 & 5 & 8.5 & 4 & 11.1 \\
\hline
\end{tabular}


Table 3. Text Descriptions of Body Size Compared with Coder Estimations

\begin{tabular}{|c|c|c|c|c|}
\hline \multirow{2}{*}{ Body Type Described in Text } & \multicolumn{5}{|c|}{ Body Size Estimated by Coders } \\
\cline { 2 - 5 } & Normal Range & Overweight & Obese & 1 \\
\hline \hline Normal range & 2 & 6 & 10 & 12 \\
\hline Overweight & 0 & 2 & 53 & 72 \\
\hline Obese & 0 & 8 & 64 & 100 \\
\hline Total & 2 & 8 & 0 & 16 \\
\hline
\end{tabular}

Note: The total number of images represented in this table (100) is less than the whole sample (199) because 19 articles did not describe the body type of the image subject

Table 4. Distribution of BMI of Subjects Described as Obese $(n=53)$

\begin{tabular}{|c|c|c|c|c|c|c|c|}
\hline Median figure rating scale score $^{1}$ & 6.0 & 6.5 & 7.0 & 7.5 & 8.0 & 8.5 & 9.0 \\
\hline Approximate BMI value & 31.0 & 32.5 & 34.0 & 35.5 & 37.0 & 38.5 & 40.0 \\
\hline Count & 0 & 0 & 7 & 7 & 14 & 8 & 17 \\
\hline Percentage & 0.0 & 0.0 & 13.2 & 13.2 & 26.4 & 15.1 & 32.1 \\
\hline
\end{tabular}

1. Median average of the four scores attributed to each image by coders using the image rating scale (Figure 1)

than those described as 'normal' weight (Table 2). Subjects described as overweight or obese had unhappy expressions more commonly than did those described as normal weight (Table 2). Only subjects described as obese were pictured engaged in activities associated with sedentary lifestyles $(n=5)$, and they were more commonly photographed eating $(n=19)$ than were those described to be of other body sizes. No subjects described as being of normal weight were untidy, wearing medical clothing, pictured with unhappy or obscured facial expressions, engaged in sedentary activities or eating (Table 2 ).

\section{DISCUSSION}

The findings help to illustrate two mechanisms by which newspapers may contribute to the normalisation of obesity. Firstly, we identified statistically significant disparity between the articles' descriptions and coders' evaluations of subjects' body sizes. Subjects were frequently of higher BMI categories than they were described in the accompanying text, suggesting that the journalists may have a tendency to underestimate their body sizes. Secondly, we showed that BMI is neither evenly nor normally distributed between subjects described by articles as obese; as nearly three quarters of these subjects represented BMI values of 37 or higher, and nearly one third represented a BMI of 40 , often categorised as 'morbidly obese' [46]. This distribution suggests that newspapers tend to use images of relatively extreme obesity to illustrate articles about obesity. In addition, the negatively skewed BMI distribution within obese subjects in the sample differs starkly from the positively skewed distribution of BMI values within the obese population of the UK [47].

These findings are not, in isolation, evidence of the normalisation of obesity. However, when considered in light of the power of news images to influence readers' perceptions [34, 35], our findings illustrate how newsprint misrepresentations may play a role in reinforcing and exacerbating misconceptions about body size. If the trends identified in this study are extant in wider mass media reporting on obesity, they may play an important role in determining societal perceptions of obesity, and therefore a role in driving the normalisation of obesity. Normalisation is important because it may prevent overweight and obese individuals from adopting healthy lifestyles, and wider society from embracing legislative solutions to obesity [17, 18].

In addition to normalisation, signs of stigmatisation were identified. The findings echoed those of previous research $[37,38]$, highlighting a tendency for newspaper photographs of overweight and obese individuals to include negative stereotypes that may reproduce weight stigma. Compared with subjects described as normal weight, subjects illustrating overweight and obesity were more frequently depicted with unhappy or neutral facial expressions, obscured heads or faces, and eating food, often junk food. Unhappy or neutral facial expressions may stigmatise overweight and obese individuals as unhappy or deserving of pity. Excluding subjects' heads or faces, while likely intended to protect the subject's privacy, may serve to dehumanise overweight and obese people. Depicting subjects eating food, while not an inherently unhealthy behaviour in itself, may serve to focus readers' attention on individual overeating as a driver of obesity to the exclusion of other drivers, which could reinforce the stereotype of the obese individual being to blame for a lack of self-control, and undermine the roles of social and environmental drivers of obesity. These trends could be harmful if found in wider mass media coverage of obesity, serving to reproduce negative stereotypes of obesity, leading to further prejudice, discrimination and damage to psychological and physical health [28]. 
Certain limitations of the research should be taken into account. Firstly, compromises were unavoidable in choosing the coding instrument. Figure rating scales are predominantly used to study body image perception, not for evaluating BMI. Furthermore, visual estimation is a much less reliable measure BMI than physical measurements. Despite this, visual estimation of BMI is used routinely by doctors, not necessarily with the aids of graphical scales, to diagnose patients' BMI [40]. In a blind study of cardiology doctors' visual estimations of BMI, Husin and colleagues [40] found that $81 \%$ of obese patients were correctly estimated to be obese, with the remaining obese patients were estimated to be overweight. Additionally, the scale used was initially designed for measuring body image perception in African Americans, while the majority of the image subjects in our sample were Caucasian, and body composition is known to vary by ethnicity [48]. While acknowledging the compromises made in choosing a scale, we are confident that the instrument represented a robust tool for a relatively novel research design. The implementation of a team of coders blind-coding each images allowed individual systematic coding biases to be eliminated. Images that were difficult to code due to their composition or the subject's pose were identified by substantial disagreement between coders, and removed accordingly, and a Fleiss Kappa test of inter-rater agreement indicated substantial agreement on the remaining images. Any uniform bias among the coders could not be detected. However, if any uniform bias existed, Husin and colleagues' [40] findings suggest that coders were likely to underestimate subjects' BMI values. If this were found to be the so, it would logically follow that the disparities between article text descriptions and image subjects' true BMI categories were greater than our findings suggest, which would strengthen the conclusion that newsprint representations misrepresent the range of body sizes classed as obese.

The second limitation of the study is its sample size. Inconsistencies in data about images in online newspaper article databases and the incompleteness of the library archive meant that the final sample of 119 articles and images was smaller than we anticipated. As a result, the trends identified in the sample cannot necessarily be generalised to wider newsprint coverage. In addition, the sample size limited our ability to analyze how variables such as publication genre and publication date related to articles' representations of obesity. Inconsistencies and incompleteness in the database and archive may also have produced the variation in the number of articles published in different publications. For example, the relatively high frequency of illustrated articles about obesity in the Mirror \& Sunday Mirror could result from between-publication variations in the way that specific elements of articles are submitted to the database.

However, there is no reason to believe that these articles and images were in any way atypical. In addition, due to the disproportionately powerful influence of news images, compared to that of article text $[34,35,36]$, it seems reasonable to suggest that the images analysed may have influenced readers' perceptions more than would text-only articles.
The third limitation of the study is inherent to content analysis; one can only describe the content of material, and cannot provide insight into its creators' motives or intentions. This is particularly relevant to newspaper articles as they can be modified by a number of individuals from inception and publication, each of whom may have different motivations. Furthermore, images may have been chosen by a picture editor working independently of the original author of the text. In addition, analysing media content alone cannot tell us what messages the audience will take away, as forming meaning is a collaborative process between the text and the audience, and the context within which the text is consumed plays a role in how it is interpreted [49]. However, regardless of the intent of publishing decisions, the final article presented to readers is important, due to the role of media portrayals in influencing public understandings of health issues [12].

Further research in this area might benefit from these limitations being taken into account in their research design. Firstly, a figure rating scale designed specifically for visually estimating BMI, with normative BMI values for each portrait, would be of value. Secondly, taking into account the difficulties inherent to sourcing newspaper articles with images, further research might benefit from focusing instead on online news articles, as did Heuer and colleagues [38]. In addition, researchers interested in images of obesity may find that images are more numerous in other news media, such as magazine articles or television news, and there may be value in comparing images in articles about obesity with images in unrelated articles. The issue of the complex authorship of newspaper articles may warrant study in itself, which could investigate the roles and motivations of the personnel involved in putting together an article. As Gibson and Zillmann [50] suggest, journalists should be aware of the potentially harmful power of news images. This study adds to evidence that could lead news media producers with an interest in accuracy and integrity to consider their editorial processes with regard to illustrative images. If editors wish to illustrate obesity to readers in an accurate, informative and socially-responsible manner, they might consider seeking illustrative images that represent the full range of body sizes within the obese category and avoiding images that reinforce negative stereotypes of obesity. Alternatively, if public health campaigners wish to combat misleading and negative images of obesity, they might consider developing informational campaigns aimed specifically at counteracting those images.

Mass media coverage can influence how ideas develop, spread and enter public discourse [12]. This study suggests that there may be a tendency for newspapers to misrepresent the range of body sizes within the obese category, and disproportionately use images of extreme obesity to illustrate general societal obesity. These trends demonstrate a possible mechanism by which newspapers might contribute to the normalisation of obesity in society. This study also contributes to existing literature on mass media stigmatisation of obesity [37, 38], demonstrating how newspapers' photographic representations of overweight and obesity could serve to reinforce stigmatisation. In conclusion, this study contributes to a growing body of literature on mass media portrayals of obesity. It does so by illustrating two ways in which newspapers' pictorial 
depictions of overweight and obesity could harm both public understanding and public healthy: by exacerbating a process of normalisation that distorts public perceptions of healthy weight; and by contributing to the stigmatisation of overweight and obesity that harms the psychological and physical health of overweight and obese individuals [28].

\section{CONFLICT OF INTEREST}

The authors confirm that this article content has no conflicts of interest.

\section{ACKNOWLEDGEMENTS}

We would like to acknowledge the help provided by the staff of the National Library of Scotland. Thanks are due to Rachel Robertson, Dr. Jenny van Bekkum, Gillian Fergie and Neil Bertram for coding the images, to Candida Fenton for conducting literature searches, and to Dr. Helen Sweeting and Prof. Dame Sally Macintyre for advising on the manuscript.

This project was funded by the Chief Scientist Office of the Scottish Government Health Directorates (MC_A540_5TK70). Data were originally collected by the $\mathrm{MRC} / \mathrm{CSO}^{-}$Social and Public Health Sciences Unit, University of Glasgow. The authors declare no conflict of interests.

\section{REFERENCES}

[1] WHO. Obesity and Overweight Fact Sheet N³11. 2012 [ cited in July 2011]. Available from: http://www.who.int/mediacentre/factsheets/fs311/en/index.html

[2] NHS. Health Survey for England 2009 Trends Commentary. In: Unit NICJHS, editor. Leeds: NHS Information Centre for health and social care 2010

[3] WHO. Obesity: preventing and managing the global epidemic. Report of a WHO consultation. World Health Organ Tech Rep Ser 2000; 894: (12), 1-253.

[4] The Scottish Government. The Scottish Health Survey: Summary of Key Findings 2010

[5] Jebb S. Obesity: causes and consequences. Women's Health Med 2004; 1(1): 38-41.

[6] Hill JO, Catenacci V, Wyatt HR. Obesity: overview of an epidemic. Psychiatr Clin North Am 2005; 28 (1):1-23.

[7] Nestle M, Jacobson MF. Halting the obesity epidemic: a public health policy approach. Public Health Rep 2000; 115(1):12-24.

[8] Hilton S, Patterson C, Teyhan A. Escalating coverage of obesity in UK newspapers: The evolution and framing of the 'obesity epidemic' from 1996 to 2010. Obesity 2012; 20(8): 1688-95.

[9] Chang VW, Christakis NA. Medical modelling of obesity: a transition from action to experience in a 20th century American medical textbook. Sociol Health Ill 2002; 24(2): 151-77.

[10] Caballero B. The global epidemic of obesity: an overview. Epidemiol Rev 2007; 29: 1-5.

[11] Townshend T, Lake AA. Obesogenic urban form: theory, policy and practice. Health Place 2009; 15(4): 909-16.

[12] McCombs M. A Look at Agenda-setting: past, present and future. Journalism Stu 2005; 6(4) :543-57.

[13] Swinburn B, Egger G, Raza F. Dissecting obesogenic environments: the development and application of a framework for identifying and prioritizing environmental interventions for obesity. Prev Med 1999; 29(6): 563-70.

[14] Lawrence RG. Framing obesity: The evolution of news discourse on a public health issue. Harvard Int J Press/Polit 2004; 9(3): 5675.

[15] Wardle J, Boniface D. Changes in the distributions of body mass index and waist circumference in English adults, 1993/1994 to 2002/2003. Int J Obes 2007; 32(3) :527-32.
[16] Johnson F, Cooke L, Croker H, Wardle J. Changing perceptions of weight in Great Britain: comparison of two population surveys. BMJ 2008; 337: a494.

[17] Chipperfield T, O’Brien R, Bolderson T, Eidinow E, Shafner L, Butland B. Tackling Obesities: Future Choices - Qualitative Modelling of Policy Options. London: Government Office for Science 2007.

[18] Keightley J, Chur-Hansen A, Princi R, Wittert GA. Perceptions of obesity in self and others. Obesity Res Clin Practice 2011; 5(4): e341-e9.

[19] Moffat T. The "Childhood Obesity Epidemic". Med Anthropol Q 2010; 24 (1):1-21

[20] Workman JE, Lentz ES. Measurement specifications for manufacturers' prototype bodies. J Cloth Text Res 2000; 18(4): 251-9.

[21] Ledikwe JH, Ello-Martin JA, Rolls BJ. Portion sizes and the obesity epidemic. J Nutr 2005; 135(4): 905-9.

[22] Butland B, Jebb S, Kopelman P, et al. Foresight. Tackling Obesities: Future Choices - Project report. 2nd ed. London: Government Office for Science 2007.

[23] Bleich SN. Public perception of overweight. BMJ 2008; 337: a347.

[24] Burke MA, Heiland FW, Nadler CM. From "overweight" to "about right": evidence of a generational shift in body weight norms. Obesity 2010; 18(6): 1226-34

[25] Vuorela N, Saha M-T, Salo MK. Parents underestimate their child's overweight. Acta Pædiat 2010; 99(9): 1374-9.

[26] Jeffery AN, Voss LD, Metcalf BS, Alba S, Wilkin TJ. Parents' awareness of overweight in themselves and their children: cross sectional study within a cohort (EarlyBird 21). BMJ 2005; 330(7481): $23-4$

[27] Duncan DT, Wolin KY, Scharoun-Lee M, Ding EL, Warner ET, Bennett GG. Does perception equal reality? Weight misperception in relation to weight-related attitudes and behaviors among overweight and obese US adults. Int J Behav Nutr Phl Act 2011; 8 $: 20$.

[28] Puhl RM, Heuer CA. Obesity stigma: important considerations for public health. Am J Public Health 2010; 100(6): 1019.

[29] Link BG, Phelan JC. Conceptualizing Stigma. Annu Rev Sociol 2001; 27: 363-85.

[30] Sandberg H. A matter of looks: the framing of obesity in four Swedish daily newspapers. Communcation 2007; 32(4): 447-72.

[31] Puhl RM, Heuer CA. The stigma of obesity: a review and update. Obesity 2009; 17(5): 941-64.

[32] Jackson TD, Grilo CM, Masheb RM. Teasing history, onset of obesity, current eating disorder psychopathology, body dissatisfaction, and psychological functioning in binge eating disorder. Obesity Res 2012; 8(6): 451-8.

[33] Ashmore JA, Friedman KE, Reichmann SK, Musante GJ. Weightbased stigmatization, psychological distress, \&amp; binge eating behavior among obese treatment-seeking adults. Eat Behav 2008; 9(2): 203-9.

[34] Knobloch S, Hastall M, Zillmann D, Callison C. Imagery Effects on the Selective Reading of Internet Newsmagazines. Commun Res 2003; 30(1): 3-29.

[35] Gibson R. Effects of photography on issue perception. In: Bryant J, Roskos-Ewoldsen D, Cantor J, editors. Communication and emotion: Essays in honor of Dolf Zillmann. Mahwah, NJ: Lawrence Erlbaum Associates 2003. pp. 323-45.

[36] Zillmann D, Gibson R, Sargent SL. Effects of Photographs in News-Magazine Reports on issue Perception. Media Psychol 1999; 1(3): 207-28.

[37] Gollust SE, Eboh I, Barry CL. Picturing obesity: Analyzing the social epidemiology of obesity conveyed through US news media images. Soc Sci Med 2012; 74(10): 1544-51.

[38] Heuer CA, McClure KJ, Puhl RM. Obesity stigma in online news: A visual content analysis. J Health Commun 2011; 16(9): 976-87.

[39] Lewis S, Thomas SL, Blood RW, Castle DJ, Hyde J, Komesaroff PA. How do obese individuals perceive and respond to the different types of obesity stigma that they encounter in their daily lives? A qualitative study. Soc Sci Med 2011; 739: 1349-56.

[40] Husin M, Kasim S, Tuthill A. Accuracy of visual estimation in diagnosing obese individuals-a blinded study. Bri J Med Practi 2012; 5(2)

[41] Williams SJ, Seale C, Boden S, Lowe P, Steinberg DL. Medicalization and beyond: the social construction of insomnia and snoring in the news. Health 2008; 12(2): 251-68. 
[42] WHO. Obesity epidemic puts millions at risk from related diseases. WHO Press Release. 1997; 46:12.

[43] Gardner RM, Brown DL. Body image assessment: A review of figural drawing scales. Personality and Individual Differences. 2010; 48(2): 107-11.

[44] Pulvers KM, Lee RE, Kaur H, Mayo MS, Fitzgibbon ML, Jeffries SK, et al. Development of a Culturally Relevant Body Image Instrument among Urban African Americans. Obesity 2004; 12(10): 1641-51.

[45] Landis JR, Koch GG. The measurement of observer agreement for categorical data. Biometrics 1977; 33(1): 159-74.
[46] The NHS Information Centre. Statistics on obesity, physical activity and diet: England, 2012

[47] National Obesity Observatory. NOO Data Factsheet: Adult Weight 2012

[48] Norgan N. Population differences in body composition in relation to the body mass index. Eur J Clin Nutr 1994; 48: S10.

[49] Burton G. Media and society: Open University Press; 2004.

[50] Gibson R, Zillmann D. Reading between the Photographs: The Influence of Incidental Pictorial Information on Issue Perception. Journalism \& Mass Comm Quart 2000 2000; 77(2):355-66.

Received: June 26, 2013

(C) Patterson and Hilton; Licensee Bentham Open.

This is an open access article licensed under the terms of the Creative Commons Attribution Non-Commercial License (http://creativecommons.org/licenses/by-nc/3.0/) which permits unrestricted, non-commercial use, distribution and reproduction in any medium, provided the work is properly cited. 